\title{
Study of anemia in hospitalised infants with special reference to its risk factors
}

\section{Patel A. H. ${ }^{1}$, Kharod Patel P. ${ }^{2}$}

${ }^{1}$ Dr. Ami Himanshu Patel, Associate Professor, ${ }^{2}$ Dr. Prarthana Kharod Patel, Assistant Professor; both authors are affiliated with Department of Pediatrics, GCS Medical Collage, Hospital and Research Centre, Ahmedabad, Gujarat, India.

Corresponding Author: Dr. Prarthana Kharod Patel, Assistant Professor, Department of Pediatrics, GCS Medical Collage, Hospital and Research Centre, Ahmedabad, Gujarat, India. E-mail: drprarthanakharod@gmail.com

\begin{abstract}
Background: Anemia is a major nutritional problem in India. Anemia in infancy and early childhood affects growth and development and is associated with increased morbidity and mortality. The aim of this study was to determine the prevalence, severity and types of anemia and study the risk factors for anemia in hospitalised infants. Methods: A prospective study was conducted at a tertiary care hospital in Western India from July 2016 to December 2017. Complete hemogram of all hospitalised infants between 6-12 months of age was done and those with haemoglobin levels $<11 \mathrm{~g} / \mathrm{dl}$ were considered anemic. Results: Out of 206 hospitalised infants,131(63.6\%) had anemia. Male: female ratio was1.3:1. The most common illness for which they were admitted was respiratory tract infections.35.1\% of the anemic infants had low birth weight, $19.1 \%$ were born prematurely and $59.5 \%$ had a history of maternal anemia. Only $42 \%$ were exclusively breast fed till 6 months of age and improper complementary feeding practices was observed in $61.8 \%$ of infants. Mild, moderate and severe anemia was seen in $41.2 \%, 50.4 \%$ and $8.4 \%$ infants respectively. The most common type of anemia was microcytic hypochromic anemia (67.2\%). Conclusion: Anemia is a major problem in infants with a high prevalence. Most infants have mild to moderate anemia and the most common type is microcytic hypochromic anemia most likely due to iron deficiency. Preterm gestation, absence of exclusive breastfeeding, consumption of cow's milk, improper complementary feeding practices and presence of maternal anemia were the risk factors found to be associated with development of anemia in the present study.
\end{abstract}

Keywords: Anemia, Infants, Iron deficiency, Risk factors

\section{Introduction}

Anemia is a major nutritional problem worldwide especially in developing countries like India. According to the National Family Health Survey (NFHS-4, 20152016) data, $58.6 \%$ of children in the age group of 6-59 months in India are anemic with a higher prevalence of $68.5 \%$ in infants between 6-11 months of age [1]. World Health Organization (WHO) considers this level of prevalence of anemia $(\geq 40 \%)$ as one of severe public health significance [2].

Anemia in infancy and early childhood affects growth and psychomotor development. It decreases resistance to infections and is associated with increased morbidity and mortality. Most cases of mild to moderate anemia

Manuscript received: $28^{\text {th }}$ September 2019

Reviewed: $8^{\text {th }}$ October 2019

Author Corrected: $15^{\text {th }}$ October 2019

Accepted for Publication: $19^{\text {th }}$ October 2019 go unnoticed and untreated as they are asymptomatic or have nonspecific symptoms such as lethargy, irritability, anorexia etc. These cases are detected incidentally by the physician when the child visits him for other illnesses.

The most common cause of anemia in children is nutritional deficiency of iron, vitamin B12 and folic acid. During the first 6 months of life, full term normal birth weight infants have sufficient stores in the body to meet their physiological needs. After 6 months of age, there is depletion of stores, poor intake of vitamins and minerals and increased requirement due to rapid growth and development making the infants prone for developing anemia. Various biological, socioeconomic, cultural and dietary factors are closely associated with occurrence of anemia in infants. These include factors 


\section{Original Research Article}

like low socioeconomic status, prematurity, low birth weight, maternal anemia and faulty feeding practices. It is important to identify these factors and study their association with the occurrence of anemia. Infants with these risk factors should be subjected to early screening as timely detection and prompt treatment will help decrease the morbidity associated with this condition.

Most studies on anaemia have been done in children between 1-5 years of age. Very few studies have exclusively studied infants aged 6-12 months. Therefore, this project was taken up to study the prevalence and pattern of anemia in infants and the determinants and risk factors associated with it.

\section{Aims and objectives}

To study the prevalence, severity and types of anemia in infants. To study the risk factors for anemia in infants

\section{Materials and Methods}

A prospective study was carried out in infants admitted in the pediatric wards at a tertiary care hospital in Ahmedabad, Gujarat, western India from July 2016 to December 2017.Institutional Ethical Clearance was taken.

Inclusion criteria: Infants between 6-12 months of age who were hospitalised due to any illness were included in the study after obtaining informed consent from the parents.

Exclusion criteria: Infants with hemolytic anemias such as thalassemia, bleeding disorders, malignancy, chronic disease, aplastic anemia and those with a past history of blood transfusion were excluded from the study.

\section{Results}

In the present study, out of the 206 infants who fulfilled the inclusion criteria,131 (63.6\%) had anemia. Out of 131 anemic infants, $75(57.3 \%)$ were males and $56(42.7 \%)$ were females with a male:female ratio of $1.3: 1.51(38.9 \%)$ infants were between 6-8 months of age and $80(61.1 \%)$ were between 9-12 months of age. Mean age of the anemic infants was 9.6 months. The most common illness for which the anemic infants were hospitalised was respiratory tract infections $(56.5 \%)$ followed by acute gastroenteritis $(26 \%)$. As per the modified Kuppuswamy classification, $17.5 \%$ infants belonged to lower socioeconomic class while $39.7 \%$ and $38.2 \%$ infants belonged to upper lower and lower middle class respectively [4]. 46 (35.1\%) had low birth weight (birth weight $<2.5 \mathrm{kgs}$ ) and $25(19.1 \%)$ were born prematurely. In 78 $(59.5 \%)$ cases there was a history of maternal anemia during pregnancy. $55(42 \%)$ were exclusively breast fed till 6 months of age while in $68(51.9 \%)$ infants there was a history of consumption of cow's milk in the first 6 months of life. Formula milk was given in $8(6.1 \%)$ patients. Faulty complementary feeding practices were observed in $81(61.8 \%)$ anemic infants with most of them on a cereal and milk-based diet with little intake of pulses, fruits and vegetables. Late weaning was noted in 31.6\% infants. Clinically, pallor was observed in 74(56.5\%) cases and pedal odema was present in 14(10.7\%) patients. As per WHO criteria, 28(21.4\%) were stunted, 24 (18.3\%) were wasted and 39(29.8\%) were underweight [5]. Table 1 shows the characteristics of the infants with anemia.

Pediatric Review: International Journal of Pediatric Research Available online at: www.medresearch.in 528|P a g e 
Table-1: Characteristics of the infants with anemia.

\begin{tabular}{|c|c|c|c|}
\hline \multicolumn{2}{|l|}{ Variable } & \multirow{2}{*}{$\begin{array}{c}\text { Number of Infants } \\
75\end{array}$} & \multirow{2}{*}{$\begin{array}{c}\text { Percentage } \\
57.3\end{array}$} \\
\hline Gender & Male & & \\
\hline & Female & 56 & 42.7 \\
\hline \multirow[t]{2}{*}{ Age } & 6-8 months & 51 & 38.9 \\
\hline & 9-12 months & 80 & 61.1 \\
\hline \multirow[t]{4}{*}{ Socioeconomic status } & Lower & 23 & 17.5 \\
\hline & Upper lower & 52 & 39.7 \\
\hline & Lower middle & 50 & 38.2 \\
\hline & Upper middle & 6 & 4.6 \\
\hline \multirow[t]{3}{*}{ Illness } & Respiratory infections & 74 & 56.5 \\
\hline & Gastroenteritis & 34 & 26 \\
\hline & Others & 23 & 17.5 \\
\hline \multirow[t]{3}{*}{ Malnutrition } & Stunting & 28 & 21.4 \\
\hline & Wasting & 24 & 18.3 \\
\hline & Underweight & 39 & 29.8 \\
\hline
\end{tabular}

Mean haemoglobin of the anemic infants was $9.3 \mathrm{~g} / \mathrm{dl}$. Mild anemia was seen in 54(41.2\%), moderate anemia in $66(50.4 \%)$ and severe anemia in $11(8.4 \%)$ patients. $7(63.6 \%)$ patients with severe anemia had congestive cardiac failure and required blood transfusion. Microcytic hypochromic anemia was the most common type of anemia and was seen in $88(67.2 \%)$ infants while $29(22.1 \%)$ had normocytic normochromic anemia. Dimorphic anemia was noted in $12(9.2 \%)$ infants and isolated macrocytic anemia in $2(1.5 \%)$ infants. On comparing the various variables between infants with and without anemia, the following observations were noted. Anemia was more common in preterm infants with $80.6 \%$ of them being anemic while only $60.6 \%$ term infants had anemia which was statistically significant. Low birth weight infants were more prone to develop anemia with $73 \%$ of them having anemia compared to 59.4\% of normal birth weight infants being anemic. Anemia was noted in $74.5 \%$ infants who were not exclusively breast fed and in $71.6 \%$ of those who consumed cow's milk, both of which were statistically significant.

Improper complementary feeding was also observed to be an important risk factor for anemia with $75 \%$ of infants with faulty feeding practices having anemia. Minimum acceptable diet was noted in only $38.2 \%$ of the anemic infants. Infants whose mothers were anemic were at an increased risk with $69.6 \%$ of them developing anemia. Prematurity, not having been exclusively breast fed for first 6 months of life, consumption of cow's milk, improper complementary feeding practices and maternal anemia were important risk factors which were found to be associated with anemia in the present study. Table 2 shows the association of various risk factors with the occurrence of anemia in infants.

Table-2: Association of risk factors with anemia in infants.

\begin{tabular}{|c|c|c|c|c|}
\hline \multicolumn{2}{|c|}{ Variable } & \multirow{2}{*}{$\begin{array}{c}\text { Infants without anemia } \\
(\mathbf{N}=\mathbf{7 5}) \mathbf{N}(\mathbf{\%}) \\
6(19.4 \%)\end{array}$} & \multirow{2}{*}{$\begin{array}{c}\text { Infants with anemia } \\
(\mathbf{N}=\mathbf{1 3 1}) \mathbf{N}(\%) \\
25(80.6 \%)\end{array}$} & \multirow{2}{*}{$\begin{array}{l}\text { P value } \\
<0.05\end{array}$} \\
\hline Maturity & Preterm & & & \\
\hline & Full term & $69(39.4 \%)$ & $106(60.6 \%)$ & \\
\hline \multirow[t]{2}{*}{ Birth weight } & Low birthweight & $17(27 \%)$ & $43(73 \%)$ & $>0.05$ \\
\hline & Normal birth weight & $58(40.6 \%)$ & $85(59.4 \%)$ & \\
\hline Exclusive & Not given & $26(25.5 \%)$ & $76(74.5 \%)$ & $<0.005$ \\
\hline breast feeding & Given & $49(47.1 \%)$ & $55(52.9 \%)$ & \\
\hline \multirow[t]{2}{*}{ Cow's milk } & Given & $27(28.4 \%)$ & $68(71.6 \%)$ & $<0.05$ \\
\hline & Not given & $48(43.2 \%)$ & $63(56.8 \%)$ & \\
\hline Complementary & Improper & $27(25 \%)$ & $81(75 \%)$ & $<0.001$ \\
\hline Feeding & Proper & $48(49 \%)$ & $50(51 \%)$ & \\
\hline Maternal & Present & $34(30.4 \%)$ & $78(69.6 \%)$ & $<0.05$ \\
\hline Anemia & Absent & $41(43.6 \%)$ & $53(56.4 \%)$ & \\
\hline
\end{tabular}

Pediatric Review: International Journal of Pediatric Research Available online at: www.medresearch.in 529|P a g e 


\section{Original Research Article}

\section{Discussion}

Out of 206 infants admitted in our hospital during the study period, $131(63.6 \%)$ infants had anemia. In a study by Sahana et al, $56 \%$ of the hospitalised infants were found to be anemic [6]. Saba et al and Verghese et al who studied anemia in children of different age groups, observed that its occurrence was maximum in infants between 6-12 months of age [7, 8]. Infants are the most vulnerable group for developing anemia. In the present study occurrence of anemia was more in 9-12 months age group (61.1\%) compared to the 6-8 months age group $(38.9 \%)$.

A similar observation was noted in a study by Rawat et al [9]. Late introduction of complementary foods and improper feeding practices in older infants lead to inadequate intake of iron rich food and development of anemia. Male: female ratio of infants with anemia was 1.3:1. Saba et al reported a male predominance with a ratio of 1.82:1 [7].

In the studies by Rawat et al and Spinelli et al, male gender was found to be a risk factor for anemia $[9,10]$. Most of the anemic infants belonged to upper lower and lower middle socioeconomic class. Silva et al observed that low socioeconomic class and low education status of parents were both associated with an increased risk of anemia [11].

There is a relationship between anemia and infections. $56.5 \%$ of anemic infants in the present study had respiratory tract infections and $26 \%$ had acute gastroenteritis. Ramakrishnan and Harish observed that anemic children were 5.75 times more susceptible to lower respiratory tract infections compared to the control group and that prevention of anemia reduces the incidence of infections [12]. Infections and infestations decrease the absorption of iron and other nutrients, impair hematopoises and worsen the anemia. Also, infections are associated with increased iron requirement and parasitic infestations can lead to blood loss anemia.

Anemia in infancy affects growth and development. In the present study, $21.4 \%$ of the anemic patients were stunted, $18.3 \%$ were wasted and $29.8 \%$ were underweight. In a study in Nepal, Siegel et al noted $30.8 \%, 18.1 \%$ and $50.7 \%$ of the infants between 4 to 17 months to be stunted, wasted and underweight respectively [13]. Soliman et al studied the association between growth and iron deficiency anemia in infants and children and found that patients with iron deficiency anemia had growth retardation which was reversed following iron therapy [14]. Anemia in infancy and early childhood is also associated with delayed development especially behavioural and cognitive delay and impaired learning and mental skills. A study by Gupta et al showed that children with iron deficiency anemia had suboptimal development score and this delayed development was variably reversible following iron therapy [15].

In the present study, anemia was more commonly seen in low birth weight and preterm infants compared to term infants and those with a normal birth weight. Shakur et al noted that haemoglobin levels in 6month old infants was higher in those with a higher birth weight [16]. Also, Joo et al observed that low birth weight infants were at a higher risk of developing iron deficiency anemia [17]. Low birth weight and preterm infants have low iron stores at birth and have a higher iron requirement for catch-up growth. Therefore, they are at a higher risk of developing anemia and require early iron supplementation.

$74.5 \%$ of the infants who were not exclusively breast fed for the first 6 months of life developed anemia. Spinellie et al found low birth weight and not having breastfed as risk factors associated with anemia in infants [10]. 71.6\% infants who were given cow's milk developed anemia.

In a study by Sahana et al, $76.2 \%$ of the anemic infants had a history of cow's milk supplementation at 2-3 months of age [6]. Cow's milk has iron with low bioavailability and also decreases absorption of iron from other dietary sources. Monajemzadeh and Zarkesh noted that the tendency to have iron deficiency anemia was $27 \%$ in exclusively breastfed infants and nearly $100 \%$ in those fed with cow's milk [18].

$75 \%$ of the infants with improper complementary feeding practices had anemia. The most common faulty practices were late weaning and a predominantly cereal and milk-based diet which was lacking in iron. Only $38.2 \%$ of the anemic infants consumed a minimum acceptable diet. The frequency of feeds in most infants was adequate and the main problem was the lack of dietary diversity with a poor intake of flesh foods, eggs, fruits and vegetables. A cereal based diet is a poor source of iron, has iron with poor bioavailability and has inhibitors of iron absorption. Poor intake of fruits, vegetables and animal foods leads to a deficiency of 


\section{Original Research Article}

nutrients like iron, vitamin B12 and folic acid and increases the risk of developing anemia. A study by Silva et al noted that intake of animal food and fruits by infants, decreased their risk for developing anemia [11]. Prolonged exclusive breast feeding beyond 6 months and late initiation of complimentary foods are risk factors for developing iron deficiency anemia.

$69.6 \%$ infants with a history of maternal anemia had anemia. Meinzen-Derr et al observed that maternal anemia was associated with a threefold increased risk of anemia in infants especially those on exclusive breastfeeding beyond 6 months of age [19].

Maternal anemia contributes to low birth weight and prematurity which increases the risk of anemia in infants. Improving maternal nutrition and supplementation with iron and folic acid during pregnancy and lactation are necessary to prevent anemia in infants.

In the present study, majority $(91.6 \%)$ of the anemic infants had mild to moderate anemia and $8.4 \%$ had severe anemia. In a study in children between 6-59 months of age by Verghese et al, maximum occurrence of severe anemia was observed in the 6-12 months age group [8].

Sahana et al noted preterm gestation, low birth weight, improper weaning techniques, consumption of cow's milk and top up feeding as important risk factors associated with development of severe anemia in infants [6].

Majority of the anemic infants in the present study had microcytic hypochromic anemia, most probably iron deficiency anemia as iron deficiency is the most common cause of microcytic hypochromic anemia in children.

Khandelia (68.4\%) and Saba et al (48.1\%) have also reported microcytic hypochromic anemia as the most common type of anemia [7,20]. Iron deficiency is still the most important cause of nutritional anemia in infants although the incidence of vitamin B12deficiency is increasing especially in infants on a purely vegetarian diet.

Full term and normal birth weight babies are born with sufficient iron stores to meet their physiological iron needs. These stores and the limited but highly bioavailable iron in breast milk ensure that there is no additional iron required until 6 months of age.
However, after 6 months, there is depletion of the iron stores and increased requirement of iron for rapid growth and brain development. Additional sources of iron in the form of iron rich complementary food, iron fortified food or iron supplements are required to prevent anemia [9]. In a study by Jain et al, it was noted that exclusive breast feeding, weaning at the correct age with right foods and iron supplementation lowered the occurrence of anemia [21].

The American Academy of Pediatrics recommends routine universal screening for anemia in infants at the age of 12 months along with assessment of risk factors for anemia [22]. WHO recommends universal supplementation of iron in low birthweight infants from the age of 2 months to 23 months and in full term infants from 6 to 23 months if the diet is poor in iron and the prevalence of anemia is $>40 \%$ [2]. Early screening for anemia especially in infants with risk factors is necessary.

Maternal education regarding maternal anemia, importance of exclusive breast feeding, and proper complementary feeding practices is essential. Effective implementation of the National Nutritional Anemia Control Programme and providing iron and folic acid supplementation to pregnant and lactating mothers and infants is required to decrease the prevalence of anemia in infants [23].

Limitations of the study: The present study had some limitations. It was a small study and was conducted only on hospitalised infants at a single centre. Estimation of serum levels of ferritin, iron, vitamin B12 and folic acid could not be done due to financial constraints. Therefore, the etiological diagnosis of anemia could not be ascertained.

\section{Conclusion}

Anemia is a major health problem in infants in the 6-12 months age group with most of them having mild to moderate microcytic anemia, most likely iron deficiency anemia. Premature gestation, presence of maternal anemia, not being exclusively breastfed for initial 6 months of life, consumption of cow's milk and improper complementary feeding practices are the risk factors associated with anemia in infancy. Maternal education, early detection of anemia by screening of infants with risk factors and increased coverage of iron supplementation and food fortification programmes are important measures which can decrease the prevalence of anemia in infants.

Pediatric Review: International Journal of Pediatric Research Available online at: www.medresearch.in 531|P a g e 


\section{Original Research Article}

\section{What this study adds to existing knowledge?}

Anemia is a major health problem in infancy with a high prevalence. Prematurity, maternal anemia and faulty breast feeding, and complementary feeding practices are the risk factors for anemia in infants.

\section{Contribution of authors}

Dr. Ami H Patel: Design of study, acquisition and analysis of data and drafting the manuscript.

Dr. Prarthana Kharod Patel: Contributed in the collection and interpretation of data and revising and final approval of article.

Funding: Nil, Conflict of interest: None initiated, Permission from IRB: Yes

Institutional Ethical Clearance: Yes

\section{References}

1. International Institute for Population Services and ICF. 2017. National Family Health Survey (NFHS-4), 2015-2016: India. Mumbai: IIPS. Available at http:/ rchiips. org/NFHS/NFHS-4 Reports/India.pdf.

2. Nutritional anemias.Tools for effective prevention and control, Geneva:World Health Organization.2017. Available at http://apps.who.int/iris/bitstream/handle / 10665 /259425/9782541513067_eng.pdf.

3. World Health Organization. Indicators for assessing infant and young child feeding practices 2010.Available at http://apps.who.int/iris/bitstream/10665/ 44368 /1/ 9789241599757 eng.pdf.

4. Kumar N, Shekhar C, Kumar P, Kundu AS. Kuppuswamy's socioeconomic status scale-updating for 2007. Indian J Pediatr. 2007;74(12):1131-1132.

5. WHO child growth standards. Length-for-age, weight- for-age, weight-for-length, weight-for-height and body mass index for age. Methods and Development. Department of Nutrition for Health and Development. Geneva: World Health Organization, 2006: 50-221. Available at http://www.who.int/ child growthstandards / Technical_report.pdf.

6. Sahana KS, Ghaliyah K, Anitha P, Prakash S. Study of anemia in hospitalized infants at a tertiary care hospital. Ntl J of Community Med. 2015;6(2):22-27.
7. Saba F, Poornima S, Balaji PA, Varne SR, Jayashree $\mathrm{K}$. Anemia among hospitalized children at a multispeciality hospital, Bangalore (Karnataka), India. J Family Med Prim Care. 2014(1);3:48-53. doi:10.4103/ 2249-4863. 130275.

8. Verghese S, Kamalakarababu SK, Vadakkedam S. Prevalence and severity of anemia among hospitalised children aged 6-59 months. J Evolution Med Dent Sci. 2017; 6 (82) :5750-5754. doi:10.14260/ jemds / 2017/ 1247.

9. Rawat R, Saha KK, Kennedy A, Rohner F, Ruel M, Menon P. Anaemia in infancy in rural Bangladesh: contribution of iron deficiency, infections and poor feeding practices. Br J Nutr. 2014;111(1):172-181. doi: 10. 1017 / S 0007114513001852. Epub 2013 Jun 17.

10. Spinelli MG, Marchioni DM, Souza JM, Souza SB, Szarfarc SC. [Risk factors for anemia among 6- to 12month-old children in Brazil]. Rev Panam Salud Publica. 2005; 17(2):84-91. doi: 10.1590/s1020-498920 05000200004 .

11. Silva DG, Priore SE, Franceschini SD. Risk factors for anemia in infants assisted by public health services: the importance of feeding practices and iron supplementation. Jornal de Pediatria. 2007;83(2):149156. doi:10.2223/JPED.1603.

12. Ramakrishnan K1, Harish PS. Hemoglobin level as a risk factor for lower respiratory tract infections. Indian J Pediatr. 2006;73(10):881-883.

13. Siegel EH, Stoltzfus RJ, Khatry SK, Leclerq SC, Katz J, Tielsch JM. Epidemiology of anemia among 4to 17-month-old children living in south central Nepal. Eur J Clin Nutr. 2006; 60(2):228-235. doi: 10.1038/sj. ejcn. 1602306.

14. Soliman AT, Al Dabbagh MM, Habboub AH, Adel A, Humaidy NA, Abushahin A. Linear growth in children with iron deficiency anemia before and after treatment. J Trop Pediatri. 2009;55(5):324-327. doi: 10. 1093/ tropej/ fmp011. Epub 2009 Mar 4.

15. Gupta SK, Bansal D, Malhi P, Das R. Developmental profile in children with iron deficiency anemia and its changes after therapeutic iron supplementation. The Indian Journal of Pediatrics. 2010;77(4):375-379. doi:10.1007/s12098-010-0046-9. 


\section{Original Research Article}

16. Shakur YA, Choudhury N, Hyder SM, Zlotkin SH. Unexpectedly high early prevalence of anaemia in 6month-old breast-fed infants in rural Bangladesh. Public Health Nutr. 2010;13(1):4-11. doi: 10.1017/S136 898 0009005886. Epub 2009 May 28.

17. Joo EY, Kim KY, Kim DH, Lee JE, Kim SK. Iron deficiency anemia in infants and toddlers. Blood Res. 2016; 51(4): 268-273. doi: 10.5045/br.2016.51.4.268. Epub 2016 Dec 23.

18. Monajemzadeh SM, Zarkesh MR. Iron deficiency anemia in infants aged 12-15 months in Ahwaz, Iran Indian J Pathol Microbiol. 2009;52(2):182-184.

19. Meinzen-Derr JK, Guerrero ML, Altaye M, OrtegaGallegos H, Ruiz-Palacios GM, Morrow AL. Risk of infant anemia is associated with exclusive breastfeeding and maternal anemia in a Mexican cohort. J Nutr. 2006;136(2):452-8. doi: 10.1093/jn/136.2.452
20. Khandelia R. A study of anemia in hospitalised infants at a tertiary care hospital. GJRA. 2007; 6 (8): $145-46$

21. Jain S, Chopra H, Garg SK, Bhatnagar M, Singh JV. Anemia in children: early iron supplementation. Indian J Pediatr. 2000; 67 (1): 19-21. doi: 10.1007/bf 0280 2628.

22. Baker RD, Greer FR; Committee on Nutrition American Academy of Pediatrics. Diagnosis and prevention of iron deficiency and iron-deficiency anemia in infants and young children (0-3 years of age). Pediatr. 2010; 126 (5): 1040-1050. doi: 10.1542/peds. 2010-2576. Epub 2010 Oct 5.

23. Kumar A. National nutritional anaemia control programme in India. Indian J Public Health. 1999;43 (1): $3-5$.

\section{How to cite this article?}

Patel A. H, Kharod Patel P. Study of anemia in hospitalised infants with special reference to its risk factors. Int J Pediatr Res.2019;6(10): 527-533.doi:10.17511/ijpr.2019.i10.06 